\title{
信息技术支持下小学英语自主阅读教学策略探究
}

蒋婵科

常州市武进区刘海栗小学

DOI:10.32629/jief.v2i6.1070

[摘 要] 随着新课改的不断深入, 英语阅读教育越来越受到小学英语教师的重视, 英语阅读教学也对小学生的英语核心素养起着重大的作用。 当今社会, 信息技术的不断发展, 小学英语的阅读教学也要采用先进的科学技术, 为学生提供良好的阅读方案, 提高小学生对于英语阅读的 学习兴趣, 对小学生的课内外阅读进行严格监管, 保证小学生的英语阅读效果, 使小学生在英语阅读的过程中, 全面锻炼小学生对英语的听、 说、写、译能力。

[关键词] 信息技术; 英语阅读; 教学探究

中图分类号: G633.67 文献标识码: A

随着信息技术的不断发展，信息技术影响着我们的生活、学习和工 作。将信息技术引入小学校园有利于提高小学生的学习效果, 弥补传统 教育的不足。在 2019 年 3 月, 教育部发布《关于实施全国中小学教师信 息技术应用能力提升工程 2.0 的意见》后，如何将小学英语的阅读教育 与先进的科学技术进行有效的结合, 是当今时代小学英语教师的一大重 要问题。信息技术的发展为小学英语阅读的教学提供了新型的教学理念 与教学模式, 因此, 小学英语教师要结合学生的实际状态与自身的教学 经验, 打造良好的信息化英语阅读教学。

\section{1 信息技术在小学英语阅读的教学的重要作用}

1.1 有助于打造多样性的英语阅读教学模式

传统的英语阅读教学注重的是的单一的朗读、跟读、解读的教和学 的模式。而信息技术的融合, 利用图片、思维导图、音频、视频动漫等 动态的方式展示英语阅读的整个学习交流的过程, 提升小学生的英语代 入式体验, 激发学习乐趣, 营造更加生动有趣的学习氛围。其次网络平 台的应用, 可以让学生不受时间限制地跟着网络内容进行学习和交流, 增加了学生自主学习和英语沟通的能力。从而进一步改变学生的学习状 态，养成有方法、有兴趣的主动学习习惯。

\section{2 有助于提升学生独立学习的能力}

新课改下, 对小学英语的学习更加注重的是阅读和沟通的能力。师 生在整个教学过程中应当有所互动和交流, 这样才能让学生了解教师的 教学方法和教授习惯, 更加适应教学课堂节奏。同时教师也可以通过学 生的学习进度和反馈情况, 掌握学生的吸收程度, 从而对英语阅读教学 内容进行适当的调整。信息技术下的英语教学侧重于线上、线下的双层 教育。线上教育可以在教师的引导下, 跟着教师进行多样化的阅读知识
技巧的学习, 鼓励学生敢于张口交流, 更正语音发音和分析的技巧, 从 而进一步丰富教学形式, 活跃教学气氛。线下教育侧重学生通过网络平 台进行自主学习和测评, 根据自身的学习差异, 进行及时的跟进和完善, 从而提升学生的巩固阅读、语句语调以及文章分析的能力。此外, 网络 平台上外教, 也可以参与到学生的提倡阅读学习训练之中, 给学生提供 母语国家的学习交流氛围, 提高英语交际能力, 让学生可以随时随地的 进行提高，从而实现英语资源的实时共享。

1.3 有助于丰富课程资源, 扩宽学生知识面

网络资源琳琅满目, 既拓宽了教师的教学知识面, 同时改进了教师 的教学内容和教学方式, 同时又给学生带来了一定的学习趣味性。毕竟 学校教学大纲要求教授的内容是有限的, 引入互联网信息技术可以获取 更多的引申知识资源, 将课本知识和互联网引进内容进行整合调整, 寻 找更适应课堂要求更有益于学生吸收的方法内容, 在很大程度上提高小 学英语阅读教学的教学成效。

\section{2 英语阅读教学现状}

四年级的小学生是英语学习的一个分水岭, 在四年级之前的英语学 习, 内容简单基础, 因此学生的水平不会出现太大的差距。但四年级阶 段, 随着学生的成长, 以及英语阅读题目的难度增加, 学生的成绩开始 有了新的变化。传统的英语阅读，教师会首先将文章中的陌生单词进行 讲解，然后让学生进行全篇的阅读，最后根据问题进行阅读理解，但这 种类型并不适用于所有小学生。针对性格比较活泼的小学生, 他们不能 很好地安静下来进行对文章的仔细阅读, 因此班级会出现两极分化现象, 有的学生很快将文章读完, 有的同学却刚刚开始, 一旦出现这种现象, 会打乱教师的整体教学进度。因此, 教师需要结合现代化的信息技术, 
对全班学生的英语阅读学习进行严格把控, 促进小学生英语素质的提高, 遵循教育部对小学生提出的要求。

\section{3 信息技术下小学英语自主阅读教学策略}

3. 1 利用 Flash 动画导入, 明确学生阅读目标

Flash 是一种制作动画视频的软件, 通常由图片与文字结合将内容 以影像的形式呈现出来, 所制作出的动画具有较强的交互性。教师可运 用 Flash 动画创设图文并茂、声像兼具的体验式英语阅读, 即让学生融 入 Flash 动画设定的阅读情境中, 将静态文字化为具有指向性的动态阅 读模板, 可使他们更明确地找出阅读目标。这种化说教为体验的教学方 式有利于增强学生的主观能动性, 并使他们在明确阅读动机的基础上初 步增强自主阅读能力。

例如: 在学习 “When is Easter?” 這课中 “read and write” 这 部分的文章时, 笔者在教学伊始利用多媒体放映了一段 Flash 动画, 动 画中动态地展示了小猫成长的四个阶段, 从一身粉红色睁不开眼睛, 到 长出白色线毛开始发出叫声, 再至眼睛完全睁开并且立起了耳朵, 最后 已经可以跑跑跳跳和人一起玩闹。这时让学生根据动画内容的指引去阅 读课文, 不仅可以轻松读懂文本内容, 还能理清故事的发展脉络, 在解 答 “read and match” 部分的习题时也可事半功倍地完成任务, 切实有 利于他们阅读理解水平的初步提升。

3.2 灵活运用微课视频, 突破学生阅读难点

微课是一种以短小精悍著称的新媒体教学工具, 它以更便捷的优势 突破了传统多媒体课件的刻板，视频利用 5 10 分钟的时间集中讲述一 个知识点, 这种针对性强、主题突出的教学方式能使学生对原本零散杂 乱的知识点理解更加透彻, 突破英语阅读难点。小学生的英语阅读能力 相对薄弱, 教师利用微课视频进行难点教学可让他们将抽象陌生的英语 知识转化为形象立体的图像, 从而使之对课文中的英语知识点留下更深 刻的印象。

如在教学 “Helping parents” 一课时, 笔者利用微课讲解了这部分 的重要知识点 “动词短语 ing 形式的用法” , 微课视频中以动画的形式 呈现了 “dancing, running, walking, climbing, flying” 与其动词原 型的区别, 学生可以直观看到动词 ing 形式均是动态的, 而动词原型皆 是静态的, 如此便可轻松地理解动词短语的 ing 形式多用在表示正在进
行的动作, 并为他们以后学习现在进行时态的语法知识奠定了基础, 由 此可见微课教学切实对帮助学生突破学习难点具有积极作用。

3.3 借助信息教学 APP, 拓展学生阅读空间

经济与文化的全球化发展将英语教育摆到了一个极为重要的位置, 社会各界人士对英语教育的重视程度也越来越高, 发展英语教育成了一 个商机, 于是越来越多的英语教育类智能 APP 出现在人们的视野中, 切 实给现代英语教学提供了极大的便利。这种形势下, 教师利用智能手机 与电脑等信息设备布置课下阅读任务, 不仅不会引发学生的抵触情绪, 还能使他们在资源丰富的网络平台中拓展阅读空间, 进而让其在多元化 的阅读素材中全面提升英语阅读水平。

首先, 教师可建立班级网络平台, 根据课堂教学内容在平台中放置 一些与之相关的阅读素材, 如在学习过 “Seasons” 这课后, 笔者在网络 平台中插入了一些描写四季景物特征的文章, 学生可依照自己喜爱的季 节进行选择性阅读, 并在阅读后写出译文作为课下作业。其次, 教师还 可让学生利用 “扇贝阅读” “有道 $\mathrm{e}$ 读” “可可英语” 等英语阅读类 APP 进行课下自主阅读, 这些以网络资源为载体的教学 APP 可让大家在丰富 多样的阅读素材中拓展阅读空间, 进而让他们在感受英语多元化的同时 充分提升自主阅读能力。

总而言之，信息技术支持下的英语教学更凸显直观形象、便捷易传 播的特点, 十分符合学生习惯于运用形象思维接收信息的认知规律。据 此, 小学英语教师应合理利用以网络资源为载体的多种信息教学工具, 在明确学生阅读目标的同时突破教学难点, 并在帮他们拓展阅读空间的 基础上增强其自主阅读能力, 从而充分提高小学英语阅读课堂的教学价 值。

\section{[参考文献 $]$}

[1]杜健兰.新课程背景下小学英语阅读教学的有效策略分析[J].新 课程,2020(38):14.

[2]陆月平.浅谈 TPR 活动深入匹配小学英语教学内容和小学生需求 [J].新课程,2020(38):92.

[3]雒玉荣.小学英语教学学生兴趣培养的几点感悟 [J]. 新课 程,2020(38):166.

[4]祝佳宁.小学英语课堂有效提问策略研究[J].新课程,2020(35):63. 